\title{
Site Suitability Evaluation for Sustainable Distribution of Hospital Using Spatial Information Technologies and AHP: A Case Study of Upper Egypt, Aswan City
}

\author{
Asmaa H. Ahmed1', Hatem Mahmoud1', Abdel Monteleb M. Aly² \\ ${ }^{1}$ Department of Architecture, Aswan University, Aswan, Egypt \\ ${ }^{2}$ Department of Architecture, Asyut University, Asyut, Egypt \\ Email: asmaahaggag2011@gmail.com,hatem3us@yahoo.com,a.monteleb@yahoo.com
}

How to cite this paper: Ahmed, A.H., Mahmoud, H. and Aly, A.M.M. (2016) Site Suitability Evaluation for Sustainable Distribution of Hospital Using Spatial Information Technologies and AHP: A Case Study of Upper Egypt, Aswan City. Journal of Geographic Information System, 8, 578-594. http://dx.doi.org/10.4236/jgis.2016.85048

Received: June 27, 2016

Accepted: October 25, 2016

Published: October 28, 2016

Copyright $\odot 2016$ by authors and Scientific Research Publishing Inc. This work is licensed under the Creative Commons Attribution International License (CC BY 4.0).

http://creativecommons.org/licenses/by/4.0/

(c) (i) Open Access

\section{Abstract}

Site selection for location of a hospital is one of the crucial policy-related decisions taken by the government. In upper Egypt, the cities suffer from a shortage and bad distribution of hospital site. The selection of the appropriate hospital site requires consideration of multiple alternative solutions and evaluation factor. We develop a Multi-Criteria Decision Support System (MCDSS) process that combines Geographical Information System (GIS) analysis with Analytical Hierarchy Process (AHP) and use this process to determine the optimum site for a new hospital in the Aswan urban area. Based on actual conditions Aswan city, we used three main factors and seven sub-factors. The main factors are urban, environmental and economic factors. An application adopting AHP process was developed to calculate weights of every factor. Spatial analysis in GIS was used to overlay and generate factors maps and suitability evaluation map. All maps are classified from 1 (low suitable) to 5 (high suitable) using spatial information technologies. The candidate sites are divided by best, good and unsuitable hospital areas. Best hospital site represents optimal sites; good hospital site can be used as back-up candidate sites. The study was found that best area (S3) is about $30 \%$, and most of these are located in the south part of the study area; good area (S2) is about $58 \%$, and most of these are located in the central part of the study area; unsuitable area (S1) is about $12 \%$, and most of these are located in the Eastern and Western parts of the study area. Finally, the study ends with an assessment of proposed sites.

\section{Keywords}

Site Suitability Evaluation, Geographic Information System (GIS), MCDSS, Hospital 
Sitting, Spatial Analysis

\section{Introduction}

Many countries and institutions pay great attention to hospital site selection. Choosing the location of a new service, such as hospital site, is an important decision-making problem for the urban planner and decision makers. Determining the best site from a number of alternative sites is a difficult and complex process. Site selection is a kind of decision-making process that requires many criteria to be weighted and alternatives to be evaluated and ranked. Integration between MCDSS and GIS is needed to solve the site selection problem as GIS is used to solve the spatial aspect of the problem and MCDSS is used to calculate weights of the factor and evaluating of alternatives [1].

GIS offers useful tools to solve site selection problem when considering spatial planning limitations. Spatial planning involves decision-making techniques that are combined with techniques such as MCDSS. Combining GIS with MCDSS methods creates the useful tool for spatial planning [2]. AHP is a powerful tool in MCDSS, especially in hierarchical decision-making. AHP decomposes a decision problem into components of different levels. Decomposition is important in decision analysis and organized decision-making process. Siddiqui et al. (1996) were the first to combine GIS and AHP procedure to solve site selection problem.

The purpose of this study was twofold. One goal was to generate site suitability map for hospital site in Aswan city. Another goal was to evaluate and rank the existing locations of a hospital in Aswan. In this study, we focus on generating suitability map and evaluate the present situation for a hospital in a study area. This study is organized into five sections. The first section discusses previous studies that dealing using GIS in location suitability and discusses background about MCDSS (AHP) in suitability analysis. An introduction of the study site, description of the data sets and factors used in the model are provided in Section 2, and illustration of the methodology is provided in Section 3. Section 4 presents the results of the study. Finally, a summary and recommendations for future work are presented in the final section.

\section{Background Literature Review}

\subsection{Literature Review}

There are many of studies that have combined applications of GIS and AHP in solving site selection problem. For example, Vatalis and Manoliadis (2002) used GIS map overlay techniques and AHP in order to find the suitable landfill sites in Western Macedonia, Greece [3]. Allen et al. (2003) have studied the development of a GIS model for locating landfill sites [4].

Higgs (2006) reported the potential of integrating multi-criteria techniques with GIS in waste facility location and documented through a review of the existing literature to highlight the opportunities and challenges facing decision makers at different stages of 
the waste facility management process [5]. Vahidnia et al. (2009) tried to select the optimum site for a hospital in Tehran using a GIS, while at the same time considering the uncertainty issue [6]. Also, there are many studies that combined GIS with MCDSS such as AHP. Also, Guiqin et al. (2009) applied GIS and AHP for solving the problem of selecting a landfill site for solid waste in Beijing, China [7]. Onut S. et al., (2010) proposed a combined MCDSS such as AHP with GIS for selecting a shopping center site in Istanbul, Turkey [8]. Also, Ali and Ebrahim (2011) used integrated fuzzy analytical network process systems with GIS for hospital site selection within the Region 5 of Shiraz metropolitan area, Iran [2]. Also, E. H. Ibrahim and S. E. Mohamed (2011) combined fuzzy analytic hierarchy process and GIS to select the best location for a wastewater lift station in el mahalla el-Kobra, north Egypt [1].

There are many of studies that have sustainable standards in site selection. Many studies can be found in literature, e.g. Şentürk et al. 2011; Gibson et al. 2011; Awoyemi, Opaluwa, 2011; Gatrell and Elliott (2009); Manzoor et al. 2009; Baz, Geymen, Er, 2009; Onah et al. 2009; Hare and Barcus 2007; Ohta et al. 2007. Finally, Asmaa, H and Hatem, M and Abdel Monteleb, M (2016) used MCDSS (AHP) to identify and calculate the weight of sustainable standards of hospital site selection in Aswan, Egypt. In our proposed system in this study, we will focus on the spatial factors that affect the urban planning of the study area. There is no evidence in the literature that any of these publications were applied to hospital site selection problem or applied in Egypt or a region within and using AHP and GIS. In this study, GIS is used to analyze and classify maps according to the determined factor and AHP is used to calculate weights of the factor using pairwise comparison [9]. Integration between GIS and AHP is used to generate the suitability map of the hospital site. Then, the proposed sites were assessed regarding the generated suitability map.

\subsection{Analytical Hierarchy Process (AHP)}

The Analytic Hierarchy Process (AHP), introduced by Thomas Saaty (1980), is an effective tool for dealing with complex decision making, and may aid the decision maker to set priorities and make the best decision. By reducing complex decisions to a series of pairwise comparisons, and then synthesizing the results, the AHP helps to capture both subjective and objective aspects of a decision. In addition, the AHP incorporates a useful technique for checking the consistency of the decision maker's evaluations, thus reducing the bias in the decision-making process [10] [11].

The AHP generates a weight for each evaluation criterion according to the decision maker's pairwise comparisons of the criteria. The higher weight is the more important the corresponding criterion. Next, for a fixed criterion, the AHP assigns a score to each option according to the decision maker's pairwise comparisons of the options based on that criterion. Finally, the AHP combines the criteria weights and the options scores, thus determining a global score for each option, and a consequent ranking. The global score for a given option is a weighted sum of the scores it obtained with respect to all the criteria. Saaty (1980) describes a suitable measurement scale for the pairwise com- 
parisons, where verbal judgments are expressed by a degree of preference: equally preferred $=1$, moderately preferred $=3$, strongly preferred $=5$, very strongly preferred $=7$ and extremely preferred $=9$. The numbers $2,4,6$ and 8 are used to distinguish similar alternatives (Brent et al., 2007). Reciprocals of these numbers are used to express the inverse relationship. The consistency index $(C D)$ is calculated as see Equation (1).

$$
C I=\frac{(y y \max -n)}{n-1}
$$

where $y y \max$ is the biggest eigenvalue of the pairwise comparison matrix. The consistency index of a randomly generated reciprocal matrix is called the random index (RI). The average RI values for matrices of orders 1 - 15 have already been generated for a sample size of 100 . The last ratio that has to be calculated is the $C R$ (Consistency Ratio). If the $C R$ is less than 0.1 , the judgments are consistent and the derived weights can be used. The formula for calculating $C R$ is simply, see Equation (2).

$$
C R=\frac{C I}{C I R}
$$

\section{Material}

\subsection{Study Area}

Located in the south part of Egypt, Aswan is a capital of its own Governorate which has a population of about 1.2 million people and covers a total area of $2807.8 \mathrm{~km}^{2}$, with $62 \%$ of its area being plain and the remaining $38 \%$ being Mountainous. The total population of Aswan metropolitan region was around 1.2 million in the year 2006. Aswan is situated $890 \mathrm{~km}$ (553 miles) to the south of Cairo and $220 \mathrm{~km}$ (137 miles) to the south of Luxor. It is the third most popular place to visit in Egypt, behind Cairo and Luxor, and is accessible in a number of ways as shown in Figure 1.

\subsection{Data Sources}

Data used in this study were assembled from a variety of sources (Table 1). The primary data from the field survey were collected through interviews and questionnaires answered by experts in the related fields of study for identifying factors that are important for the sustainable distribution of hospital in Aswan city along with statistics data, Global Positioning System (GPS) field survey data and other GIS datasets. The GISbased land suitability analysis has been applied in a wide variety of situations including sites and administrative boundaries.

\section{Methodology}

Figure 2 shows the framework used in this study and methodology. The initial stage is data collection stage, in which spatial data about the problem is collected and experts' measurements of the factor as well. There are three phase determined in our methodology. Phase I related to GIS analysis, covering converting collected vector maps to raster and spatial analysis functions (distance analysis and reclassify). While calculating 


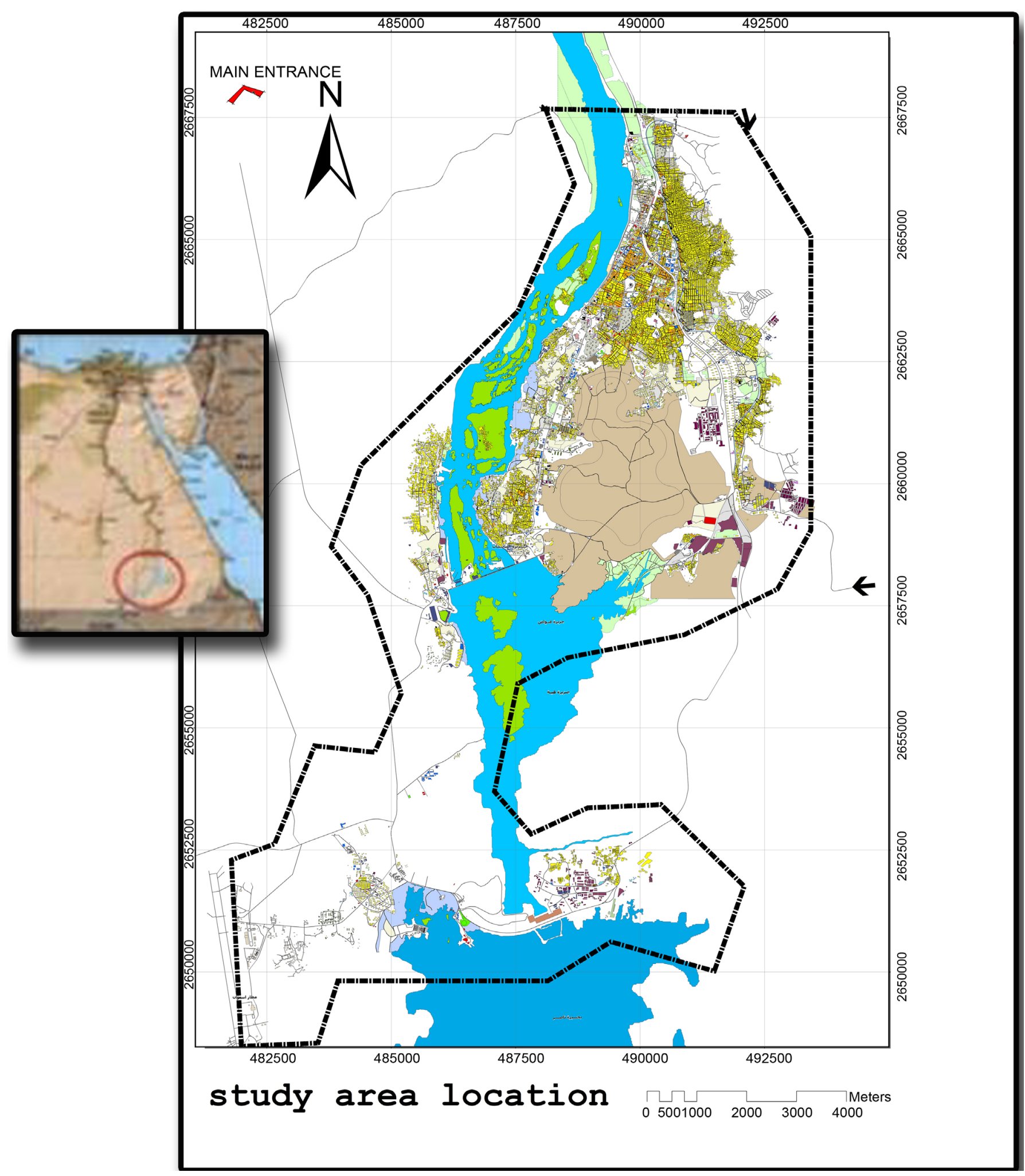

Figure 1. Location of study area.

factor weights is in phase II using a developed tool adopting AHP principal and also 


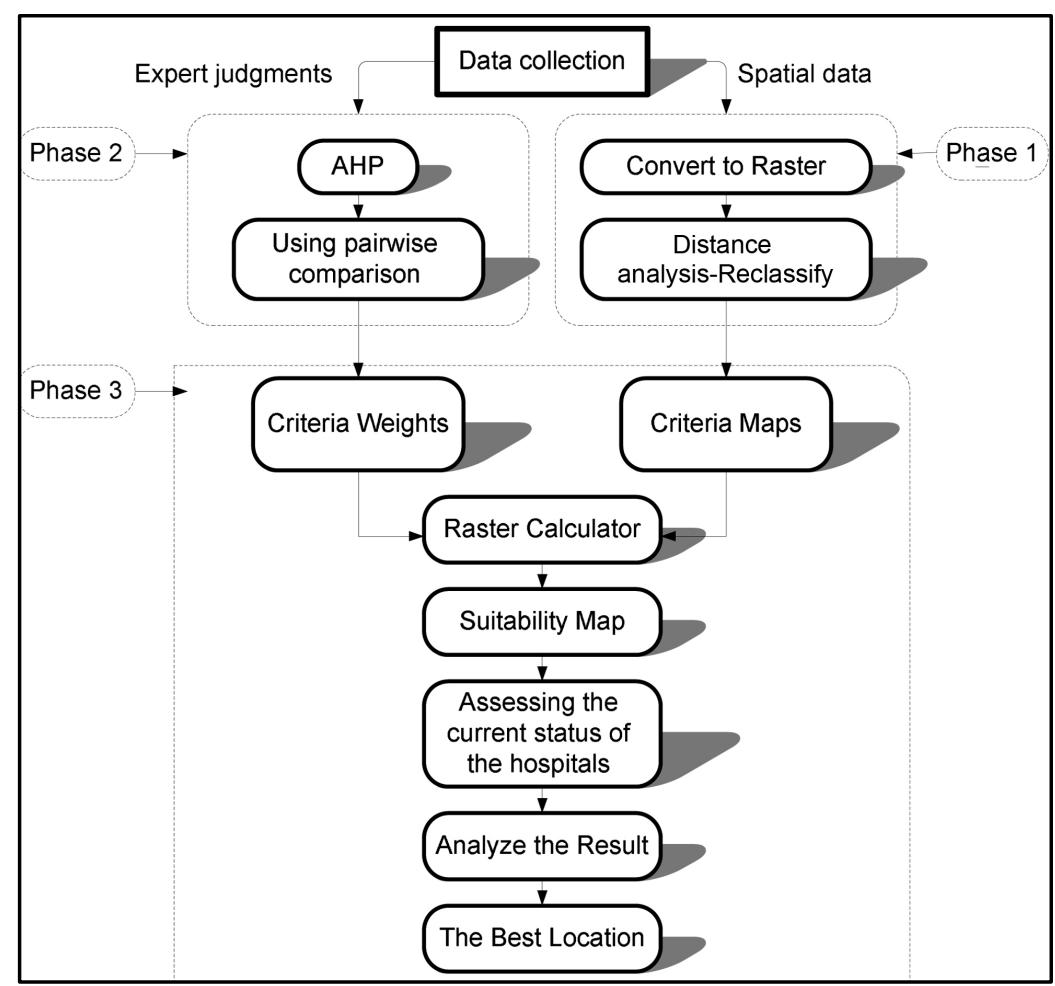

Figure 2. Methodology of the study.

Table 1. List of data and their original sources.

\begin{tabular}{ccccc}
\hline Data & Format & Scale & $\begin{array}{c}\text { Year } \\
\text { production }\end{array}$ & Source \\
\hline Land used/cover map 2006 & Tiff file & $1: 100,000$ & 2006 & \\
Hospital map & GIS file & $1: 250,000$ & 2006 & National \\
Road map & Tiff file & $1: 250,000$ & 2006 & Fundamental \\
Map noise sources & GIS file & $1: 250,000$ & 2006 & Geographic \\
Transport routes map & Tiff file & $1: 250,000$ & 2006 & Information \\
Environmental pollution points map & GIS file & $1: 250,000$ & 2006 & Center \\
Green area coverage map & GIS file & $1: 250,000$ & 2006 & \\
\hline
\end{tabular}

calculate the Consistency Ratio for the verification of the consistency of the input data. Finally, phase III in which the integration between factor weights and Maps is accomplished producing the suitability map which has the best locations for a hospital.

\subsection{Determination of Weight Value for Each Criterion Using AHP}

The hierarchy of hospital location was establishing and Figure 3 is the decision hierarchy model of hospital location in the case. We used seven criteria in the computation process, which were divided into three main groups. The first group includes environmental criteria that limit the analysis to a particular geographic area; the second group is economic factors and the third group is urban factors. The examined criteria were 


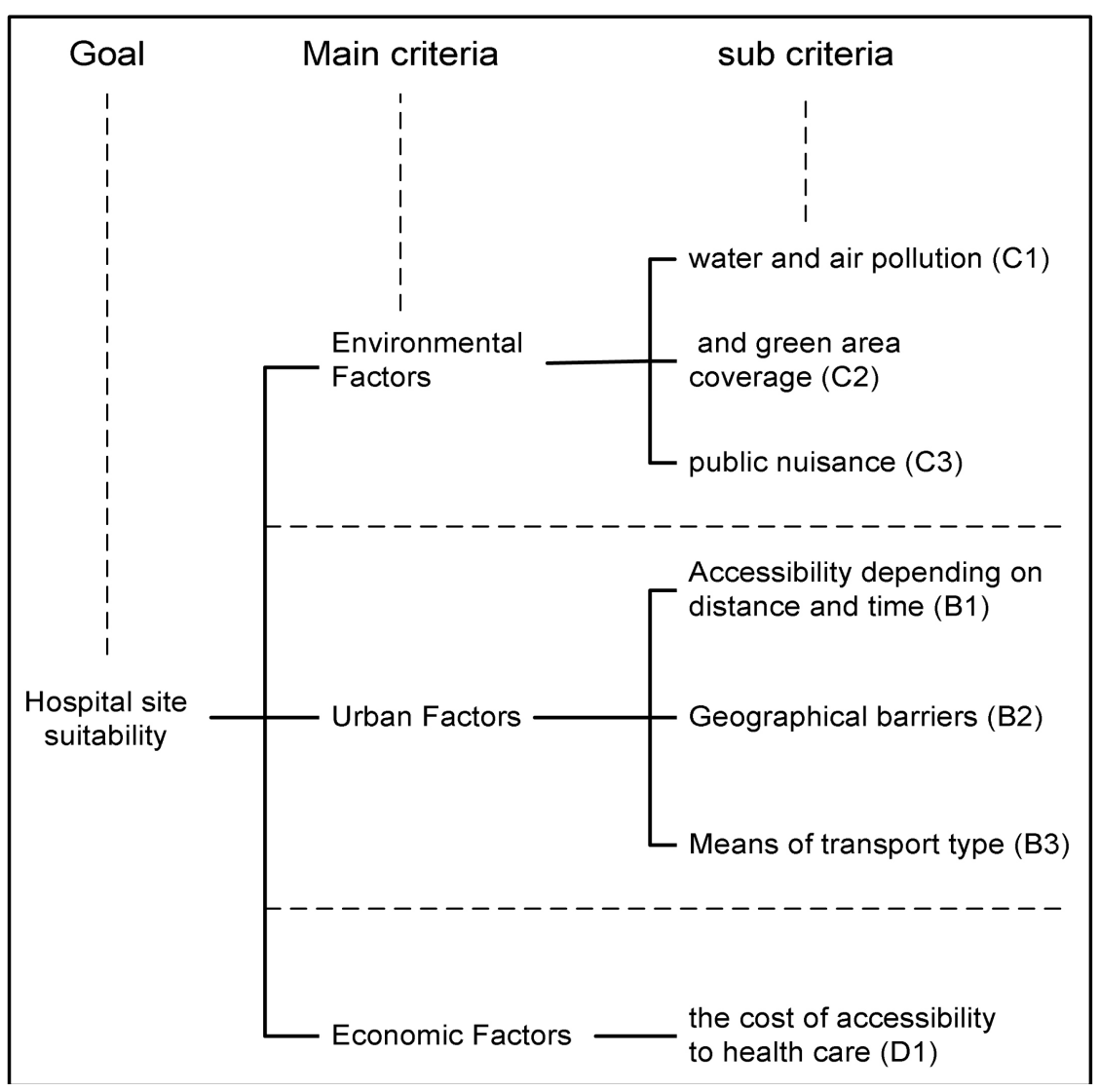

Figure 3. Hierarchy model of hospital site suitability.

selected based on the relevant international literature [1]-[12] and the regulations (N36-1984, GB 16889) in Egypt on hospital location. All criteria are shown in Figure 3.

Pairwise comparisons were used to establish the relative importance of hierarchy elements. Decision makers evaluated the importance of pairs of grouped elements in terms of their importance to the higher hierarchy. Finally, all the values for a given attribute were pairwise compared. The weight $(\mathrm{W})$ of each factor in each hierarchy was calculated by their structural models (Tables 2-5). Criteria weight (Wi) was calculated (Table 6) by normalizing the weight (W) of each factor. Wi is the criteria weight, i.e. The CR values of all comparisons were lower than 0.10 , which indicated that the use of the weights was suitable (Eastman, 2003).

\subsection{Criteria Description and Application}

In this study, seven input map layers including Water and Air pollution, Green area coverage, Public nuisance, Accessibility depending on time and distance (Access Road), Means of transport type, Geographical barriers, Cost of access to hospital and data were obtained from Aswan Institute of Geology. And its scale is 1:250,000 (Table 1). The land use map was obtained from the National Fundamental Geographic Information Center. Its scale is 1:100,000 (Table 1). The other maps were obtained from the National Fundamental Geographic Information Center too, and their scale is 1:250,000 
Table 2. Pairwise comparison of environmental factors.

\begin{tabular}{cccc}
\hline Factor & C1 & C2 & C3 \\
\hline Water and air pollution (C1) & 1 & 3 & 3 \\
Public nuisance (C2) & $1 / 3$ & 1 & 1 \\
Green area coverage (C3) & $1 / 3$ & 1 & 1 \\
Total & 1.67 & 5 & 5 \\
\hline
\end{tabular}

Table 3. Weight of environmental factors.

\begin{tabular}{cccccc}
\hline Factor & C1 & C2 & C3 & Sum & Weight \\
\hline Water and air pollution (C1) & 0.6 & 0.6 & 0.6 & 1.8 & 0.6 \\
Public nuisance (C2) & 0.2 & 0.2 & 0.2 & 0.6 & 0.2 \\
Green area coverage (C3) & 0.2 & 0.2 & 0.2 & 0.6 & 0.2 \\
Total & 1 & 1 & 1 & & $\mathrm{CI}=0.001$ \\
& & & & & $\mathrm{RI}=0.58$ \\
& & & & $\mathrm{CR}=0.002<10 \%$ \\
\hline
\end{tabular}

Table 4. Pairwise comparison of urban factors.

\begin{tabular}{cccc}
\hline Factor & B1 & B2 & B3 \\
\hline Accessibility (B1) & 1 & 3 & 5 \\
Geographical barriers (B2) & $1 / 3$ & 1 & 2 \\
transport type (B3) & $1 / 5$ & $1 / 2$ & 1 \\
Total & 1.53 & 4.5 & 8 \\
\hline
\end{tabular}

Table 5. Weight of urban factors.

\begin{tabular}{cccccc}
\hline Factor & B1 & B2 & B3 & Sum & Weight \\
\hline Accessibility (B1) & 0.65 & 0.67 & 0.63 & 1.95 & 0.65 \\
Geographical barriers (B2) & 0.22 & 0.22 & 0.25 & 0.69 & 0.23 \\
transport type (B3) & 0.13 & 0.11 & 0.12 & 0.36 & 0.12 \\
Total & 1 & 1 & 1 & & CI $=0.00$ \\
& & & & & RI $=0.58$ \\
& & & & CR $=0.00<10 \%$ \\
\hline
\end{tabular}

Table 6. Weight of main factors and sub-factors.

\begin{tabular}{|c|c|c|c|c|}
\hline Factor & Weight (w1) & Sub-factors & $\begin{array}{l}\text { Weight } \\
\text { (w2) }\end{array}$ & $\begin{array}{c}\text { Weight } \\
(w 3)=w 1^{*} w 2\end{array}$ \\
\hline \multirow{3}{*}{$\begin{array}{l}\text { Environmental } \\
\text { factor }\end{array}$} & & Water and Air pollution $(\mathrm{C} 1)$ & 0.6 & 0.24 \\
\hline & 0.4 & Public nuisance (C2) & 0.2 & 0.08 \\
\hline & & Green area coverage (C3) & 0.2 & 0.08 \\
\hline \multirow[t]{2}{*}{$\begin{array}{l}\text { Economic } \\
\text { factors }\end{array}$} & 0.1 & Cost of access to hospital (D1) & 1 & 0.1 \\
\hline & & Accessibility (B1) & 0.65 & 0.325 \\
\hline \multirow[t]{3}{*}{ Urban factor } & 0.5 & Geographical barriers (B2) & 0.23 & 0.115 \\
\hline & & transport type (B3) & 0.12 & 0.06 \\
\hline & & & \multicolumn{2}{|c|}{ Sum $=1$} \\
\hline
\end{tabular}


(Table 1). Reclassify operations were built and divided into five grades according to these criteria. Each grade was assigned a different score (1 - 5).

1) Environmental factors [12]

- Water and Air pollution: The hospital site must be away from environmental pollution points. Whenever, the site away from the pollution points was more suitable. We can reclassify the environmental pollution points map from 1 (lowest suitability) to 5 (highest suitability) using spatial information technologies in GIS.

- Green area coverage: The hospital site must be close to Green area coverage. Whenever the hospital site is close to Green area coverage was more suitable. We can reclassify the Green area coverage map from 1 (highest suitability) to 5 (lowest suitability) using spatial information technologies in GIS.

- Public nuisance: The hospital site must be away from the Public nuisance. Whenever, the site away from the Public nuisance was more suitable. We can reclassify the geographical barriers map from 1 (lowest suitability) to 5 (highest suitability) using spatial information technologies in GIS.

2) Urban factors [12]

- Accessibility depending in time and distance (Access Road): The hospital site must be close to the road network. Whenever, the hospital site is close to the road network was more suitable. We can reclassify the road network map from 1 (highest suitability) to 5 (lowest suitability) using spatial information technologies in GIS.

- Means of transport type: The hospital site must be close to Means of transport type. Whenever the hospital site is close to Means of transport type was more suitable. We can reclassify the Means of transport type map from 1 (highest suitability) to 5 (lowest suitability) using spatial information technologies in GIS.

- Geographical barriers: The hospital site must be away from geographical barriers such as mountains, railway, and Distance from residential areas. We consider Distance from residential areas as main geographical barriers because other barriers are On the edge of the study area and not effect on this study. Whenever, the site away from the geographical barriers was more suitable. We can reclassify the geographical barriers map from 1 (lowest suitability) to 5 (highest suitability) using spatial information technologies in GIS.

3) Economic factors [12]

- Cost of access to hospital: We can calculate the cost of access to a hospital by using pass way public transport in a study area. We can use public transport pass way map. The hospital site must be close to public transport pass way. Whenever the hospital site is close to public transport pass way was more suitable. By using distance operation, we can reclassify the distance map from 1 (lowest suitability) to 5 (highest suitability) using spatial information technologies in GIS.

\subsection{Assessment and Analysis}

In this process, the site suitability map for the hospital has been created, based on the linear combination of each used factor's suitability score as shown in Equation (3). The 
AHP method was applied to determine the relative importance of all selected factors. The total suitability score "Si" for each area unit (i.e. each raster cell in the map) was calculated from the linear combination of suitability score obtained for each factor and factor involved [13].

$$
S i=\sum_{i=1}^{n}(w i * R i)
$$

In this study, layers overlay, to raster conversion, clipping processes using GIS function. A GIS-based generic site suitability model using a weighted linear combination (WLC) that consist of three operations; the first operation is converting factors maps to raster format, the second operation is distance operation (Figure 4), and the third
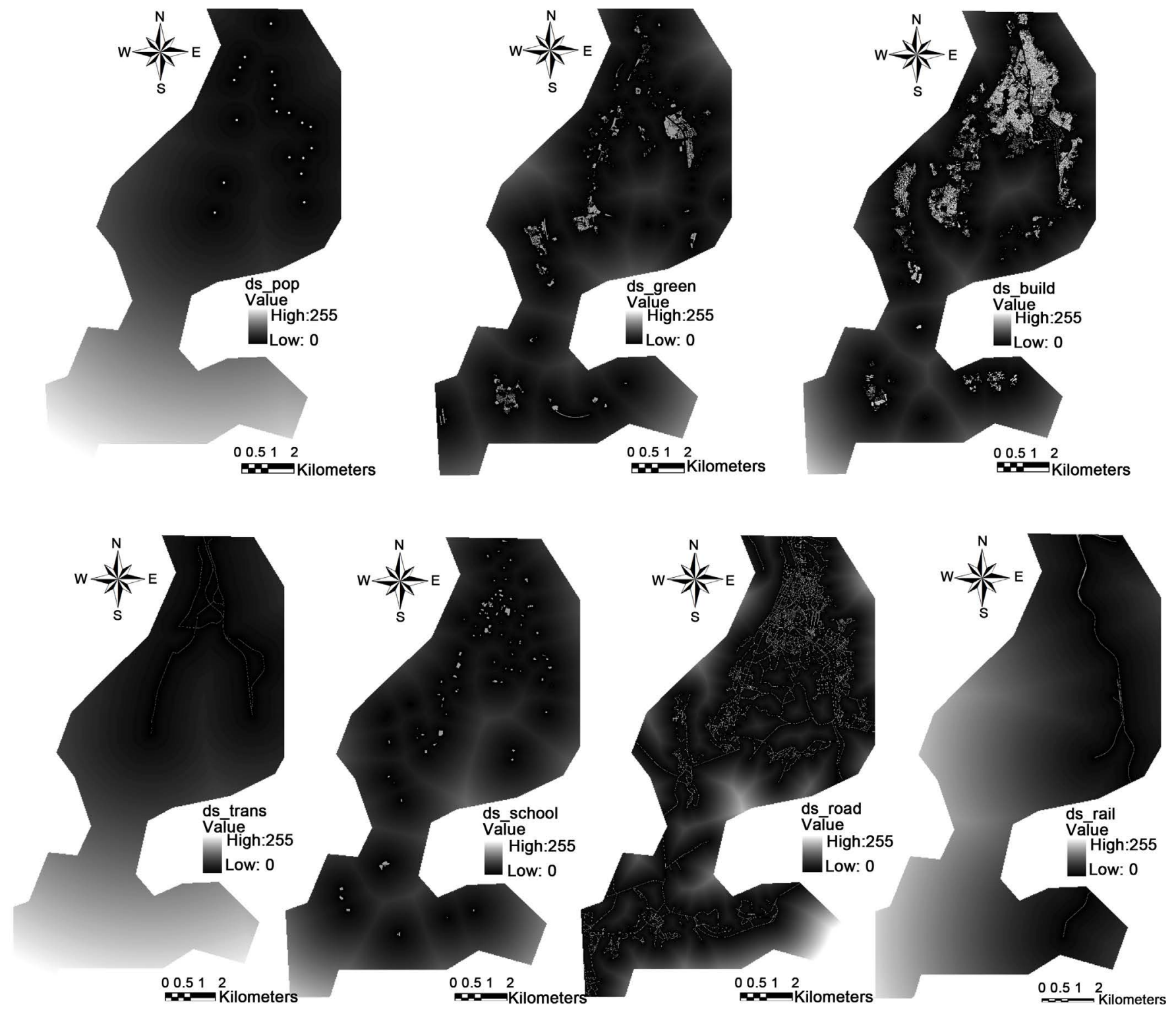

Figure 4. The layers after applying distance operations for 6 sub-criteria. (a) (Dis-pollution); (b) (Dis-green area); (c) (Dis-house building); (d) (Dis-transportation pass); (e) (Dis-school "noise"); (f) (Dis-road); (g) (Dis-railway "noise"). 
operation is reclassified operation (Figure 5) [13].

The study area was rasterised into $5 \mathrm{~m} \_5 \mathrm{~m}$ grid cells. All subfactors in the categories were quantified using a common scale, i.e., a 0 - 255 byte grading value. The grading value 0 was assigned to the least suitable areas and 255 to the most suitable ones, transforming the different measurement units of the factor images into comparable suitability values. Finally, suitability map for the hospital will be generated. Suitability map resulted by integrating factor weights from AHP with the factor maps into raster calculator function in ARG/GIS software, see Figure 6.

This result will present a rank of best and unsuitable areas, see Figure 7. After generating suitability map for all pixel in a study area, the land use will be calculated with
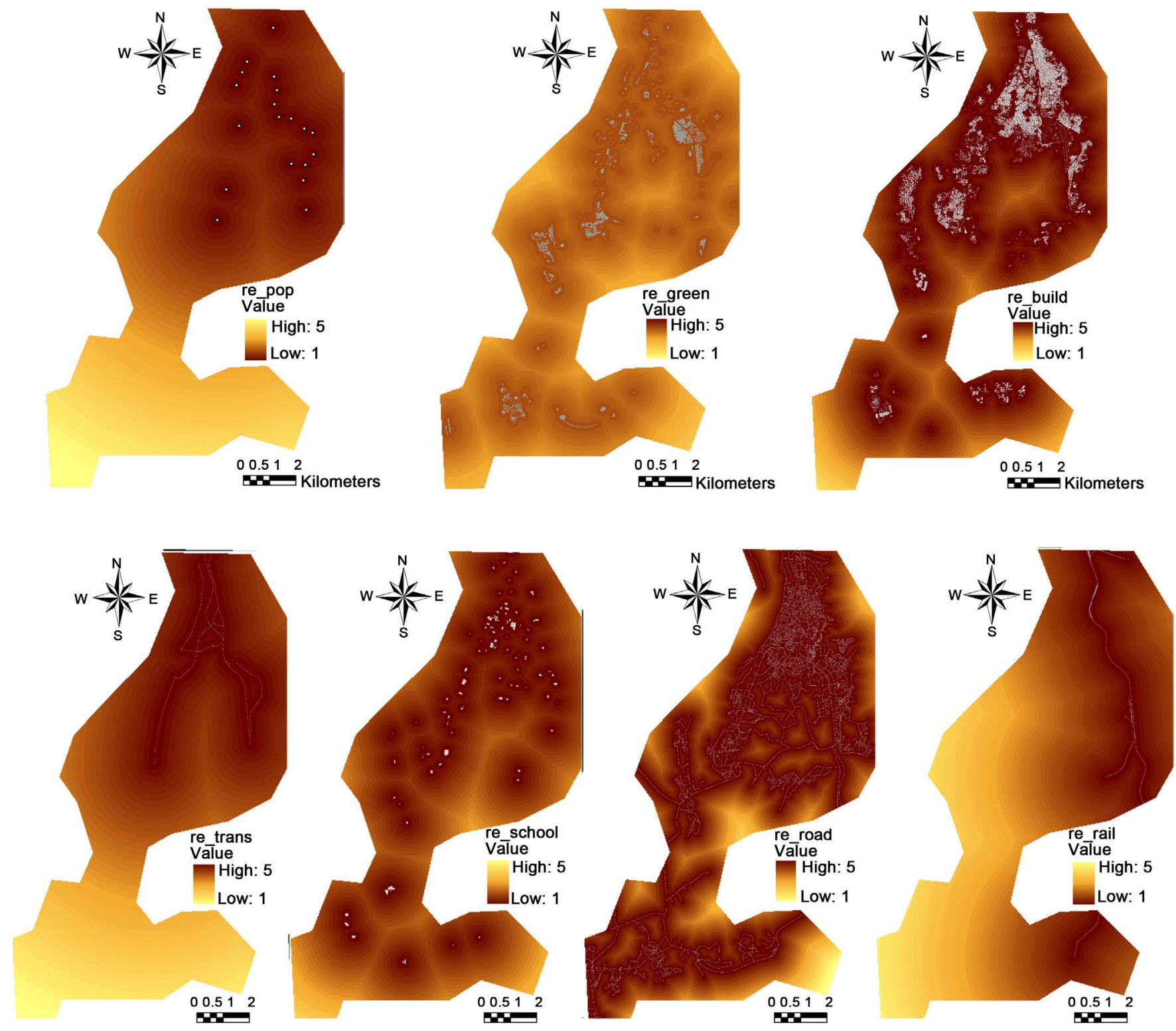

Figure 5. The layers after applying spatial analysis-reclassify operations for 6 sub-criteria. (a) (Ric-pollution); (b) (Ric-green area); (c) (Ric-house building); (d) (Ric-transportation pass); (e) (Ric-school "noise"); (f) (Ric-road); (g) (Ric-railway "noise"). 


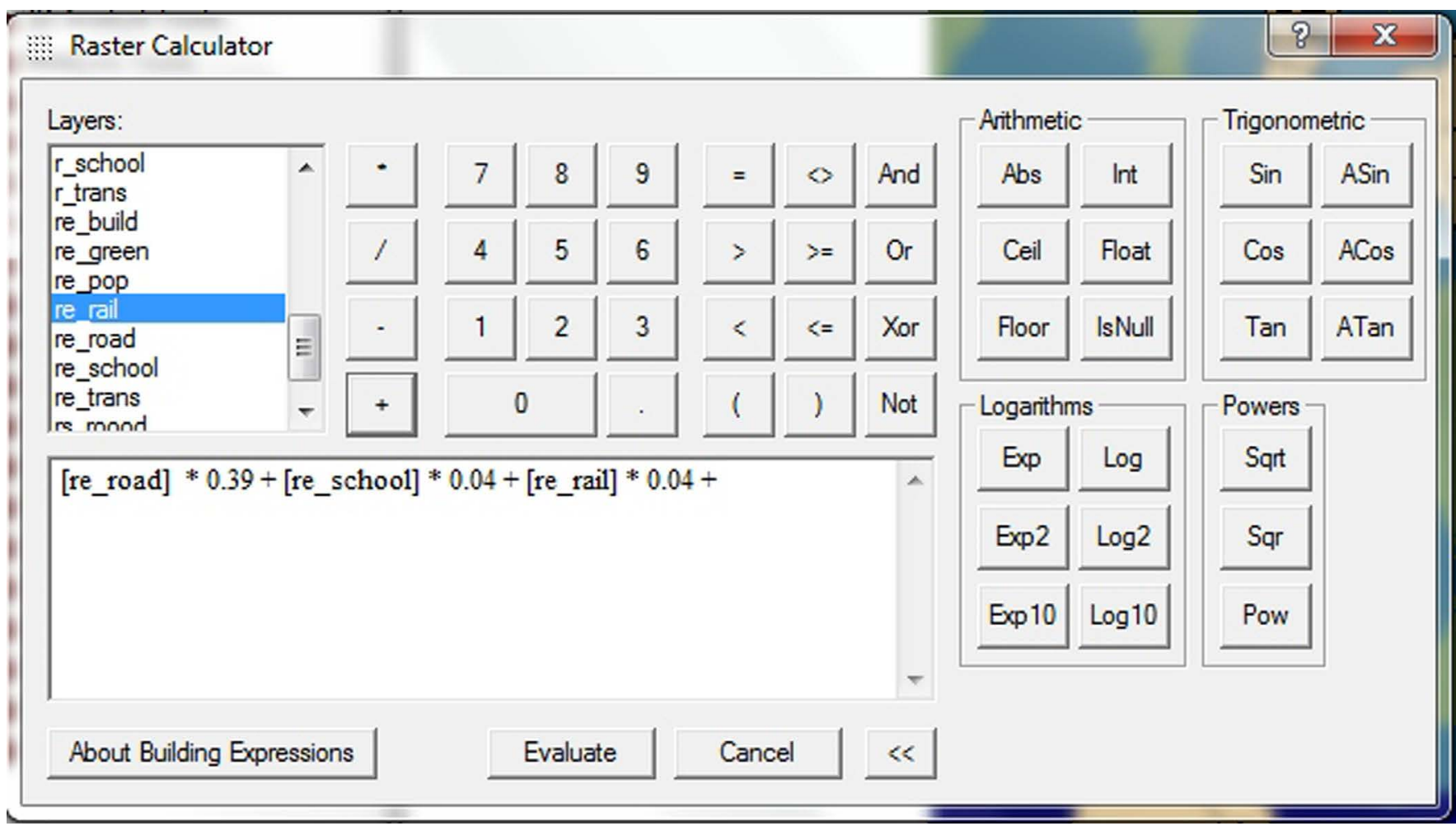

Figure 6. Raster calculating function.

suitability map. We can calculate suitability map by operating raster calculation. Factors map that show in Figure 5, and factors weight are used to calculate suitability map by using raster calculating function. A hospital site suitable map can be calculated after operating overlay and Boolean operation. This result will present all unoccupied and suitable sites that can use as hospital site and its ranking that are divided into three classes: best site, good site and unsuitable site (Table 7).

Best hospital sites represent optimal sites; good hospital sites can be used as back-up candidate sites. This study used Boolean function in raster calculated operation to extract unoccupied area from a land use suitable map and using overlay operation in GIS environment to generate buffer zone around exist hospital sites.

\subsection{Aggregation Procedure and Results}

Factor weights are given in Table 6 after standardizing all factors. The sum of all factors is 1 . Corresponding maps with all factors were reclassified from grade 1 to 5 by spatial information technologies. The score was assigned based on the grade of each area. Then, the final suitability map (Figure 7 ) is produced by aggregation procedure based on weight. The final suitability results were divided into three discrete categories: best hospital areas, good hospital areas, and unsuitable hospital areas, as shown in Figure 7.

\section{Discussion}

We present a case study that utilizes spatial information technologies (GIS) and MCDSS 


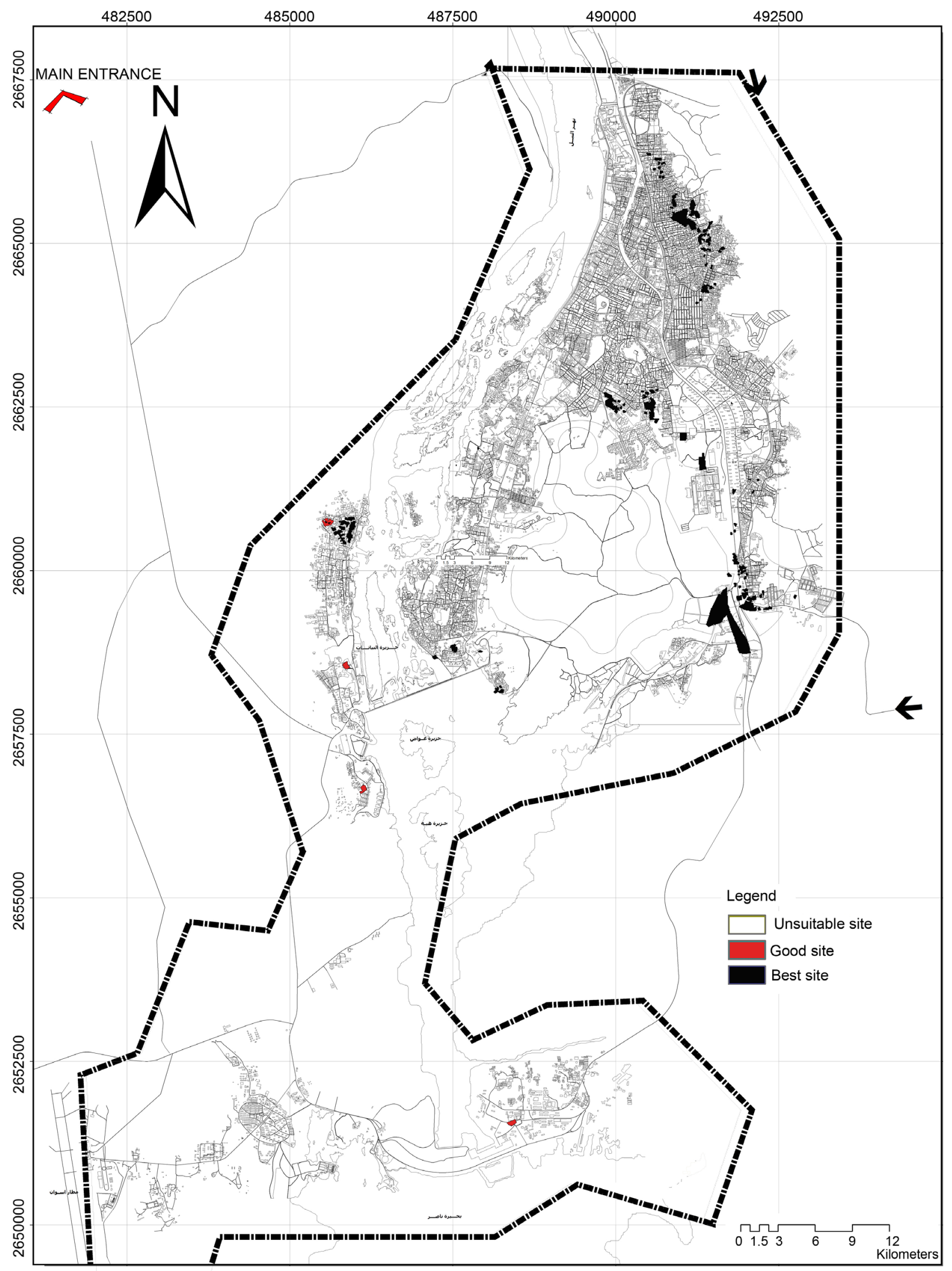

Figure 7. Suitable sites. 
Table 7. Sit suitability result.

\begin{tabular}{ccc}
\hline Suitability rate & Ranking site & Number of areas \\
\hline S3 & Best sites & 15 \\
S2 & Good sites & 125 \\
S1 & Unsuitable sites & 6 \\
\hline
\end{tabular}

(AHP) in assessing and selecting hospital candidate sites. Optimal and back-up sites were selected for hospital candidate sites in Aswan, Egypt. We also propose an MCDSS model to incorporate information from environmental, economic and urban factors, and offer a reference for hospital site selection in the future. Because this study takes into account both environmental, economic and urban criteria, the process by which the model selects hospital sites is suitable for rapidly developing cities in developing countries. We set a different weight for criteria by using pairwise comparison. A classification scheme was applied for criteria.

Data in the maps are divided to represent 3 suitability classes according to the FAO framework for land evaluation, namely, best area, good area, and unsuitable area. From the suitability map for a hospital as seen in Figure 8, it was found that the best area (S3) is about $30 \%$ and these are located in the bottom part of the study area. The good area (S2) is about $58 \%$ and these are in the central part of the study area and unsuitable area (S1) is about $12 \%$ and these are in the Eastern and Western parts of the study area.

We achieved our objective through the application of order weights. It is clear that assignment of factor weights is based on previous knowledge of the factor characteristics and the particularities of the study area, as well as on the experience of the experts involved in the weight assignment process. A weight was assigned as objective as possible by applying techniques like the AHP. In the final aggregation process, factor weights are evaluated by both factors, urban, environmental and economic, as they both play a very important role in hospital site selection.

\section{Conclusions}

The increase of a population in the Egypt is one of the greatest challenges faced by governmental authorities. The development of our model is motivated by the sustainability factors that help in solving the problem of population growth. The study focused on special factors that can modeled in MCDSS.

Multi-Criteria Decision Support System (MCDSS) is a new approach based on combine GIS with AHP. It is an appropriate methodology to support location choice and land suitability assessment. We have integrated GIS and MCDSS in the assignment of site suitability for a hospital. Only special factors were considered in the computation process, including three factors, namely, environmental, economic and urban factors that consist of seven criteria categorized in three factors. Intermediate suitability maps were produced for all criteria, which were combined to create the final composite suitability map. AHP offered an objective weight assignment process. Furthermore, the use of the set of weights provided great flexibility in the aggregation procedure. 


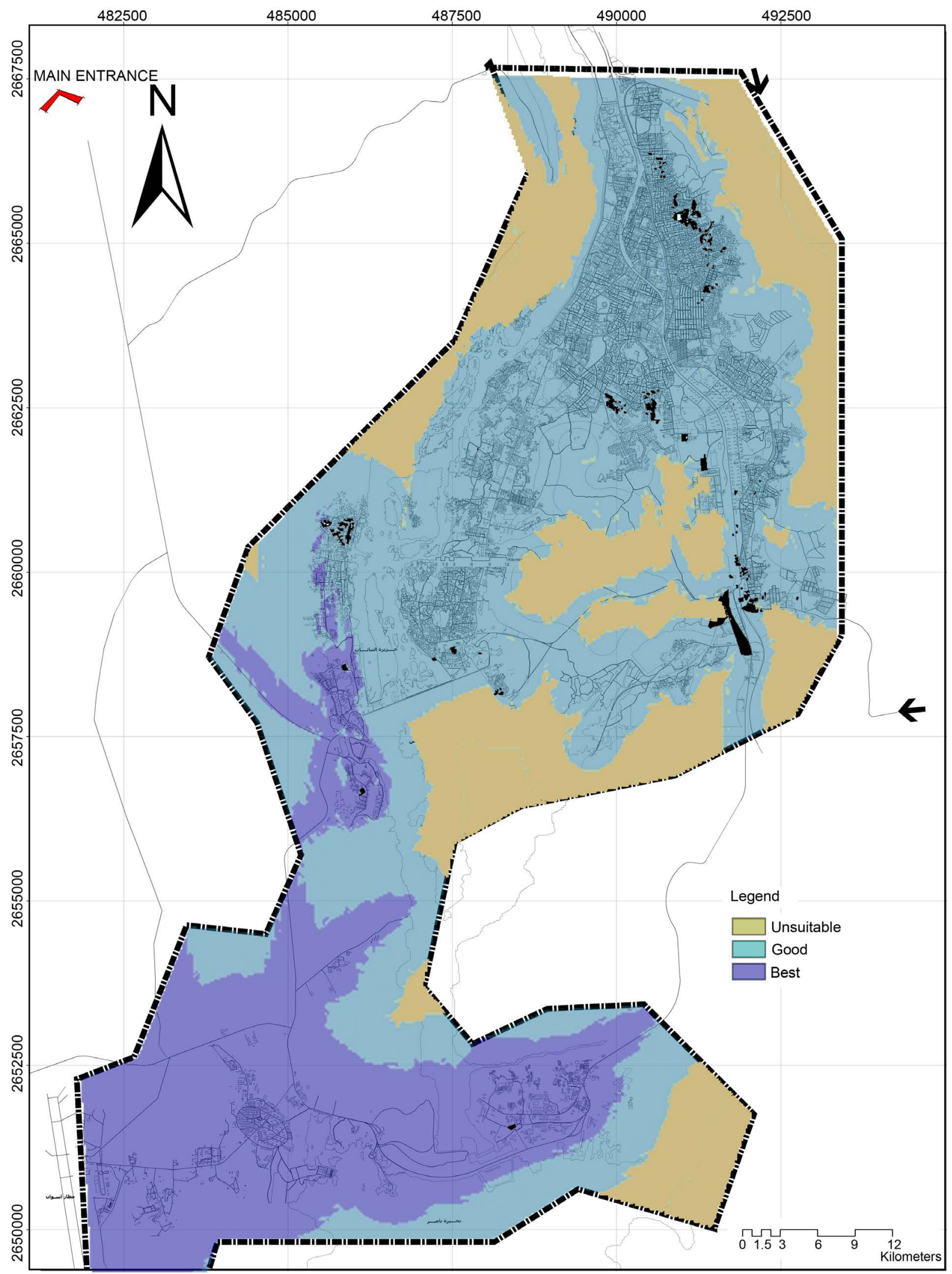

Figure 8. Final suitability map. 
Our study provided scientific evidence for the study area. Furthermore, economic factors should be considered for hospital site selection. The economic factors are very important factors for developing countries and districts. Hospital sites are selected not only according to urban and environmental factors but also economic factors. The siting process in this study will be very useful for hospital site selection in a fast-growing region.

The development of hospital is further enhanced by geospatial approaches. This study is an integrated approach to hospital development by identifying hospital sites and constructing a methodology to assess the hospital site sustainability by matching the characteristics of an area with those attributes most appropriate for health service. This method has been proven beneficial for supporting decision-making for planning health facilities for sustainable development.

The present work offers a location methodology and essential support to the decision-maker in solving the site selection problem so that a deeper understanding can be gained in environmental decision-making. In future research, we recommend examining the suitability of other AHP approaches and MCDSS methods to this site selection problem. It would also be useful to develop a high-performance application for hospital site selection based on the spatial decision-making process described herein.

\section{Acknowledgements}

The author gratefully acknowledges financial support from Aswan University. Gratitude is also extended to the reviewers and the Editor of the paper.

\section{References}

[1] Ibrahim, E.H., Mohamed, S.E. and Atwan, A.A. (2011) Combining Fuzzy Analytic Hierarchy Process and GIS to Select the Best Location for a Wastewater Lift Station in El Mahalla El-Kobra, North Egypt. International Journal of Engineering \& Technology, 11, 44-50.

[2] Soltani, A. and Ebrahim, Z. (2011) Hospital Site Selection Using Two-Stage Fuzzy MultiCriteria Decision-Making Process. Journal of Urban and Environmental Engineering, 5, 3. http://dx.doi.org/10.4090/juee.2011.v5n1.032043

[3] Vatalis \& Manoliadis (2002) A Two-Level Multicriteria DSS for Landfill Site Selection Using-GIS: Case Study in Western Macedonia, Greece. Journal of Geographic Information and Decision Analysis, 6, 49-56.

[4] Allen, et al. (2003) Landfill Site Selection Process Incorporating GIS Modeling. Proceedings Sardinia 2003, Ninth International Waste Management and Landfill Symposium, Cagliari, 6-10 October 2003.

[5] Higgs, G. (2006) Integrating Multi-Criteria Techniques with Geographical Information Systems in Waste Facility Location to Enhance Public Participation. Journal of Waste Management Research, 24, 105-117. http://dx.doi.org/10.1177/0734242X06063817

[6] Vahidnia, M.H. and Alesheikh, A.A. (2009) Hospital Site Selection Using Fuzzy AHP and Its Derivatives. Journal of Environmental Management, 90, 3048-3056. http://dx.doi.org/10.1016/j.jenvman.2009.04.010

[7] Wang, G.Q., et al. (2009) Landfill Site Selection Using Spatial Information Technologies and AHP: A Case Study in Beijing, China. Journal of Environmental Management, 90, 
2414-2421. http://dx.doi.org/10.1016/j.jenvman.2008.12.008

[8] Onut, S., et al. (2010) A Combined Fuzzy MCDM Approach for Selecting Shopping Center Site: An Example from Istanbul, Turkey. Journal of Expert Systems with Applications, 37, 1973-1980. http://dx.doi.org/10.1016/j.eswa.2009.06.080

[9] Ocampo, L. and Clark, E. (2015) A Proposed Framework in Developing Sustainable Manufacturing Initiatives Using Analytic Hierarchy Process (AHP). Journal of Industrial and Systems Engineering, 3.

[10] Malczewski, J. (2006) Ordered Weighted Averaging with Fuzzy Quantifiers. International Journal of Applied Earth Observation and Geoinformation, 8, 270-277. http://dx.doi.org/10.1016/j.jag.2006.01.003

[11] Linkov, I., et al. (2007) Multi-Criteria Decision Analysis to Select Metrics for Design and Monitoring of Sustainable Ecosystem Restoration. Journal of Ecological Indicators, 26, 7686.

[12] Asmaa, A., Hatem, M. and Monteleb, M. (2016) Multi-Criteria Decision Support System to Evaluate the Sustainable Distribution of Health Services in Upper Egypt Using Analytical Hierarchy Process. Journal of Engineering Sciences.

[13] Drobne, S. and Lisec, A. (2009) Multi-Attribute Decision Analysis in GIS. Informatica, 33, $459-474$.

Submit or recommend next manuscript to SCIRP and we will provide best service for you:

Accepting pre-submission inquiries through Email, Facebook, LinkedIn, Twitter, etc. A wide selection of journals (inclusive of 9 subjects, more than 200 journals)

Providing 24-hour high-quality service

User-friendly online submission system

Fair and swift peer-review system

Efficient typesetting and proofreading procedure

Display of the result of downloads and visits, as well as the number of cited articles

Maximum dissemination of your research work

Submit your manuscript at: http://papersubmission.scirp.org/

Or contact jgis@scirp.org 